matter present does not undergo material change, no matter how much the amount present may vary. The results with Boston tap water at intervals of several months and with differing dilutions of the same sewage show this. In order to further test this, and to see if it were really possible to differentiate the organic matter in water by this means, the following experiment was made. Two samples of water were prepared, one of which (a) was known to be free from sewage but contained considerable coloring-matter of vegetable origin; the other $(b)$ was distilled water containing a definite quantity of sewage. These gave the same amount of oxygen consumed by the permanganate process, $(a)=0.2387$ and $(b)=0.2375$ parts per 100,000 . The ratios, however, differed widely, $(a)=0.827$, and $(b)=$ 0.372 . The method was also tried on a sample of well water which gave by the permanganate test more oxygen consumed than was warranted by its color. The question to be decided was whether the organic matter was due to sewage or to the infiltration of surface water carrying vegetable substances. The ratio obtained was high, 0.957 , indicating that surface water was the cause. This was confirmed later by an examination of the well. These results certainly show that the method is quite promising and deserves further study by those chemists who are especially interested in the question of sanitary water analysis.

Massachuset's INSTITCTE OF TECHNOLOgY, APRIL 20, I898.

\title{
AN EFFICIENT GAS-PRESSURE REGULATOR.
}

\section{By PAUL MURRILI. \\ Received April 18, 1898 .}

$T$ is well known that the various types of mercury thermo1 regulators cannot cope with marked changes in the gas pressure, and for this reason it is almost impossible to maintain a constant temperature for a considerable length of time with any degree of certainty. Numerous contrivances for regulating the pressure have been proposed at various times, and several are to be had from the principal dealers, but they either fail entirely in their purpose, or are impracticable for general use owing to cost, difficulties of construction, etc. The apparatus of Moitessier, as catalogued in this country and Europe, appears 
to have some features in common with the one described below, but its cost bars it from general use. The Girond rheometer, as modified by Schiff,' was tested in connection with a mercury thermostat, with results showing it to be useless for that purpose. A pressure regulator made of glass, described by Schiff, ${ }^{2}$ is quite similar in principle to the one here described, but has the disadvantages of being quite fragile, besides requiring skilled glassblowing in its construction. An apparatus by Knudsen is also described, ${ }^{2}$ but is too complicated to be practical.

Having experienced the same difficulties that many other workers have, the attempt was made to devise a simple apparatus which would deliver gas at constant pressure regardless of the various changes of pressure in the gas-pipes. The apparatus having proved satisfactory, a description of it is given. Its strong points are efficiency, simplicity, durability, and cheapness. It can be made of sheet metal, preferably copper, by any sheet-metal worker, or may be obtained from the Eberbach Hardware Co., Ann Arbor, Mich., at a cost of $\$ 3.00$, or may even be constructed of glass, using articles found in almost every laboratory. It is designed to be used in connection with a thermostat, and with it the temperature may be held constant within $0.1^{\circ} \mathrm{C}$. Using the regulator here described, Prof. F. G. Novy has succeeded in maintaining constant temperatures in an air-bath at $50^{\circ}$ and an oven at $150^{\circ}$ at the same time.

The dimensions can be varied to suit the purpose of the operator, but those here given will be found suited to the usual

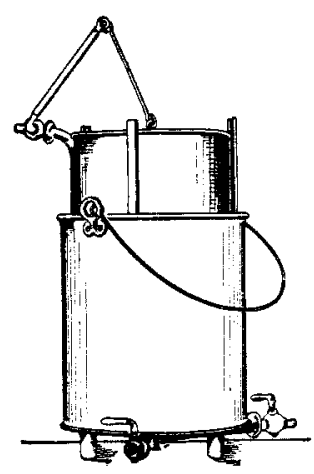
needs. The outer vessel or pail is fifteen $\mathrm{cm}$. in diameter and eighteen cm. deep. Through the center of the bottom three tubes enter, rising $14.5 \mathrm{~cm}$. above the bottom. Beneath it the tubes bend at right angles, and diverge or may be run horizontally in any convenient direction. Two of these run a short distance beyond the vessel, terminating in stop-cocks, and serve as exit tubes for the gas. The third, which is the inlet tube, bends upward at the lower edge, and extends eight $\mathrm{cm}$. a Ber. d. chem. Ges., 5885,2833 ; Ztschr. anal. Chem., $1886,385$.

2 Ztschr. anal. Chem., $1886,3^{8} 3$. 
(three inches) above the top of the outer vessel, turns outward at right angles again, and terminates in a stop-cock placed horizontally. To this stop-cock a ten $\mathrm{cm}$. lever arm is attached. On the inside of the vessel three vertical $U$-shaped grooves are soldered, extending eight $\mathrm{cm}$. above the top. The tubing should be not less than seven mm. internal diameter.

The inner vessel or gas container is thirteen $\mathrm{cm}$. in diameter and fifteen $\mathrm{cm}$. deep. On the outside three vertical flanges are soldered, corresponding to the three grooves in the outer vessel, and projecting sufficiently to

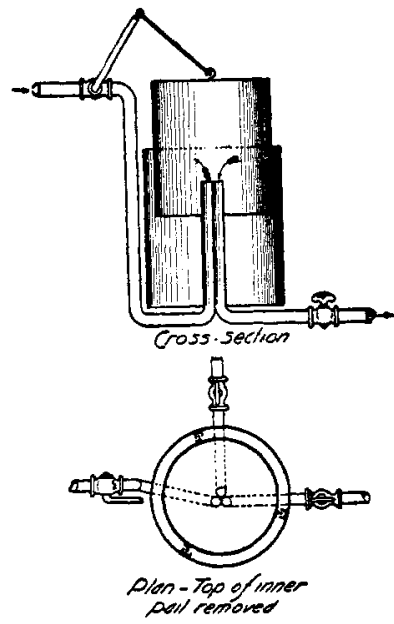
prevent rotation or lateral motion of the inner vessel, but allowing it to move freely up or down. To the top of the inner vessel is soldered a stiff wire ring, and this is connected to the end of the lever-arm of the stop-cock described above by means of a stiff wire of such length that the stop-cock is wide open when the inner vessel is in its lowest position. The inner vessel with attachments should weigh about 700 grams, under which weight the gas will be delivered at about forty $\mathrm{mm}$. pressure, but by means of convenient weights placed upon the float the pressure at which the gas is delivered may be varied at will. (In the laboratory here the maximum observed pressure in the gas-pipes is eighty-seven $\mathrm{mm}$., and the minimum forty $\mathrm{mm}$., measured on a water manometer.) The outer vessel is to be

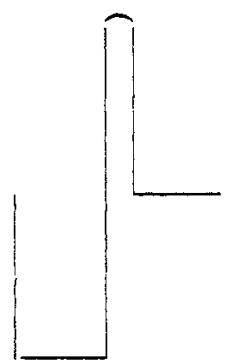
filled with water to the depth of about thirteen $\mathrm{cm}$., or instead of water, liquid paraffin may be used, avoiding evaporation. It may also be made of glass as follows: Two battery jars with straight sides, and whose diameters differ by an inch, serve as pail and float. Instead of entering through the bottom, glass tubing is bent as herewith shown, and enters between the two vessels. Three such tubes are bent, and placed at equal distances from each other. The tubing should have an 
external diameter a little less than half the difference between the internal diameter of the large jar and the external diameter of the small one, and should extend ten cm. above the top of the outer vessel, serving instead of the flanges and grooves. A glass stop-cock with as large capacity as possible is clamped rigidly in convenient position above the apparatus, and to it a lever arm of light wood is bound. To the end of the arm another light sliver or a wire is attached, which rests on the float and operates the valve.

Operation of regulator is as follows: One of the exit tubes may be connected to a manometer, or both may go to burners as may be desired. Gas enters through the stop-cock and long tube into the container, and in so doing lifts the container, at the same time closing the valve. If outlets are closed the container will rise until the valve is entirely closed, in which position it will stand. When the exit tubes are opened the container falls, reopening the valve, admitting gas at the same rate at which it is consumed, and delivering it at a pressure which is measured by the weight of the inner vessel, plus or minus the resistance due to friction. If the apparatus is well made the resistance amounts to only one or two $\mathrm{mm}$. On the manometer, and it is only exerted during the changes of position of the container. If the pressure in the pipes falls to that in the apparatus, the float falls to the bottom, opening the valve to its fullest capacity, and allowing the gas to flow through unhindered.

Thanks are expressed to Mr. J. T. Faig for the sketches herewith given, and to Professors P. C. Freer and F. G. Novy for assistance rendered in various ways.

IABORATORY OF GENERAL CHEMISTRY,

UNIVERSITY OF MICHIGAS, ANN

ARBOR, APRIL I4, 1898 .

\section{USE OF HYDROFLUORIC ACID IN THE DETERMINATION OF MANGANESE IN IRON AND ORES.}

By ALIEN P. FORD AND I. M. BREgOWSKY. Received May :3, 1898 ,

\footnotetext{
WILLIAMS' method for the determination of manganese is not faultless but is nevertheless the best method for the iron chemist who has to determine manganese in iron, steel, ferromanganese, and ores.
} 